\title{
Improvement of Chitinase produced from Chitin of Desert Locust by Streptomyces halstedii strain Isolated from Jeddah, KSA
}

\author{
Manal E. Shafi ${ }^{1}$ and Abd El-Nasser A. Khattab ${ }^{2}$ \\ ${ }^{1}$ Department of Biological Sciences, Zoology, King Abdulaziz University, Jeddah 21589, Saudi Arabia. \\ ${ }^{2}$ Department of Genetics and Cytology, National Research Centre, Dokki, Cairo, Egypt.
}

Correspondence Author: Manal E. Shafi, Department of Biological Sciences, Zoology, King Abdulaziz University, Jeddah 21589, Saudi Arabia. Email: meshafi@kau.edu.sa

Received date: 12 December 2019, Accepted date: 28 January 2020, Online date: 31 January 2020

Copyright: (C) 2020 Manal E. Shafi et al., This is an open-access article distributed under the terms of the Creative Commons Attribution License, which permits unrestricted use, distribution, and reproduction in any medium, provided the original author and source are credited.

\begin{abstract}
It is important to degrade the chitin of the collected desert locusts from Saudi Arabia to maximize benefit from it. So, many of Streptomyces isolates from soil was assayed to the chitinase production after grown on medium containing $0.5 \%$

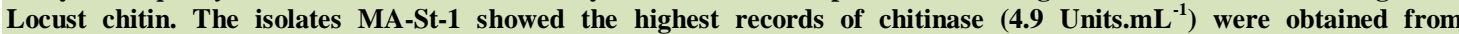
Streptomyces (MA-St-1) strain. The Streptomyces (MA-St-1) was identified as of Streptomyces halstedii through BLAST analysis of the obtained 16S-ribosomal RNA gene. The fermentation process was optimized and resulted in an additional $16.33 \%$ improvement in the chitinase of the MA-St-1 strain. The induced mutants were generated from isolated Streptomyces halstedii MA-St-1, after Ultra Violet (UV) and Ethyl Methane Sulfonate (EMS) treatments. About 44 mutants were examined and the mutant E/60-12 was the highest $\left(11.8 \mathrm{U}^{-\mathrm{ml}^{-1}}\right)$ in chitinase production with 2.07 fold higher than the parental strain. Using random amplified polymorphic DNA (RAPD) by PCR, many different DNA banding patterns were observed. And finally, to divide the mutants under study into clusters, the phylogenetic tree was drowning and the genetic diversities of the novel chitinase mutants as well as the parental strain were detected according to the genetic distances.
\end{abstract}

Keywords: Desert-locust-chitin, Streptomyces, chitinase, optimization, genetic-diversity.

\section{INTRODUCTION}

The desert locust, Schistocerca gregaria, is an economically harmful pest of many crops in many parts of Africa and Asia. Major outbreaks have occurred in Saudi Arabia, Yemen, Eritrea, Somalia, Madagascar and Ethiopia [7]. The chitin degradation of collected desert locust into low molecular weight called Chito- oligomers is done by chitinases from different sources of microorganisms. There are many various applications of chitinase [49]. Chitinase takes great care due to its part in the biocontrol of harmful pests [29] and biocontrol of fungal phytopathogens [28]. Chitinases may be used to convert chitin-containing biomass like desert locust into useful components. Chitinase obtained from $S$. marcescens was used by their group to hydrolyze the chitinous material and $P$. kudriavzevii yeast, to produce single-cell protein (SCP) that was acceptable as aquaculture feeding. Also, the SCP production from chitinous waste has been applied using chitinase from $M$. verrucaria and S. cerevisiae [47]. Also, an important medical use for chitinases for example, antifungal drugs for fungal diseases therapy [34] and a host defense effector in the immune system of mammalian [8].

Various chitinases have been detected in various Streptomyces sp., such as S. antibioticus [15], S. griseus [44], S. plicatus [37] and S. lividans [30]. Streptomyces sp. MT7 was isolated from the soil and it produces, chitinase, protease, glucanase and a highaffinity iron-chelating compound. It exhibits a wide range of activity against wood-rotting fungi [31]. Streptomyces lydicus showed an antifungal activity [26].

Streptomyces halstedii, S. cavourensis SY224 and S. griseus gave chitinases with a highly effective as antifungal. In order to increase the productivity and minimize the cost of production, it is very important to optimize of the medium used for chitinase production and study the effect of different environmental conditions [10] [43] [45] [14] [1] [20] [42].

The Streptomyces development has been exhibited by mutagenesis, conjugative mechanism, fusion of parental protoplasts, and cloning DNA methods for antibiotics and enzymes productivities [3]. One mutant of Streptomyces sp. was producing high 
amount of extracellular chitinase [46]. Moreover, the recombinant strain SU-1 obtained from S. fradiae gave higher chitinase productivity in comparison with the original strain [3].

The pathway of our study was to screen the most superior chitinolytic Streptomyces strains from a soil sample and optimize their fermentation conditions to increase the chitinase productivities. Also, this work was prefaced to link the UV and EMSmutagenesis advantages with the excellent Streptomyces isolate to obtain chitinase overproducing mutants and molecular typing of the excellent mutants with random amplified polymorphic DNA (RAPD) assay by polymerase chain reaction (PCR) in comparison with the parental strain.

\section{MATERIALS AND METHODS}

\section{Chitin preparation}

It prepared from the powdered exoskeleton of the Desert Locust using the traditional method according to [17]. The fifty grams of the powder was immersed in $4 \mathrm{M} \mathrm{HCl}$ solution $(50 \mathrm{~mL})$ at $75^{\circ} \mathrm{C}$ for 2 hours to eliminate catechols and minerals. After that, the sample was filtered off and rinsed the residue using distilled water. By using $50 \mathrm{~mL}$ of $4 \mathrm{M} \mathrm{NaOH}$ solution for $20 \mathrm{~h}$ at $150^{\circ} \mathrm{C}$, the filtrate was treated to deproteinization. The mixture was filtered off and washed twice by distilled water. Finally, the chitin was dried using an oven at $60^{\circ} \mathrm{C}$ for 24 hours. The dried chitin then washed successively in $2 \mathrm{~N} \mathrm{HC} 1$ and dried at $50^{\circ} \mathrm{C}$ in vacuo.

\section{Chitinase producing actinomycetes isolation}

Soil samples from different places of Jeddah, KSA, were placed in the sterile culture tubes. The tubes were labeled properly and stored at $4^{\circ} \mathrm{C}$. Isolation of bacteria was performed by suspending $1 \mathrm{gm}$ of the soil sample in $9 \mathrm{ml}$ sterile distilled water. The mixture was vortexed vigorously and serially diluted up to $10^{-3}$ in sterile water. An aliquot of $0.1 \mathrm{ml}$ from each dilution was taken and then spread evenly over the surface of FM in plates and incubated overnight at $37^{\circ} \mathrm{C}$. The chitinase production of all the isolates was screened by plate agar assay and followed by tests in broth for chitinase production. The fermentation medium (FM) contained $\left(\mathrm{g} \mathrm{l}^{-1}\right)$ : Locust chitin 5; yeast extract 5; $\left(\mathrm{NH}_{4}\right)_{2} \mathrm{SO}_{4} 1 ; \mathrm{MgSO}_{4} \cdot 6 \mathrm{H}_{2} \mathrm{O} 0.3 ; \mathrm{KH}_{2} \mathrm{PO}_{4} 1.36$; and agar 15 [4]. The production of chitinase was done in shake culture $(10 \mathrm{ml}$ medium $/ 50 \mathrm{ml}$ Erlenmeyer flask $)$ incubated at $30{ }^{\circ} \mathrm{C}$ in the incubator

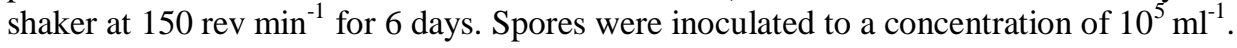

\section{Cultural optimization of chitinase production}

Locust chitin concentration: Seven levels of chitin $(0.25,0.5,0.75,1.0,1.25,1.5$ and $2.0 \%)$ were tested for their effect on chitinase synthesis in the fermentation medium.

Cultivation temperature: Fermentation was done at various temperatures $\left(30,35,40,45\right.$ and $\left.50^{\circ} \mathrm{C}\right)$ and chitinase production was monitored as a role of temperature.

Initial medium pH: Growth was carried out in fermentation medium at various initial pH values $(7,7.5,8,8.5$ and 9$)$ and chitinase production was monitored after 4 days of fermentation.

Carbon source: Growth was carried out as previously described utilizing the following carbon sources $(0.1 \%$, w/v): glucose, galactose, fructose, xylose, sucrose, lactose, carboxymethyl cellulose, and xylan.

Nitrogen source: Yeast extract, peptone, meat extract, beef extract, ammonium nitrate, sodium nitrate and potassium nitrate) were examined for their function on chitinase synthesis. The medium used in this experiment contained $(0.5 \%$, w/v) of different amounts of nitrogen sources.

\section{Molecular identification of bacteria}

Deoxyribonucleic acid (DNA) was extracted from the Streptomyces strain (MA-St-1, Jeddah, KSA) using the protocol of GeneJET Genomic DNA Purification Kit (Thermo K0721, Thermo-Fisher Scientific, Inc., Waltham, Massachusetts, USA). The PCR amplification of 16S-ribosomal gene was performed by using Maxima Hot Start PCR Master Mix (Thermo K1051, Thermo-Fisher Scientific, Inc., Waltham, Massachusetts, USA) and the nucleotide sequences of the 16S primers used are: forward primer-5'- CGGGATCCAGAGTTTGATCCTGGTCAGAACGAACGCT -3' and reverse primer-5'CGGGATCCTACGGCTACCTTGTTACGACTTCACCCC-3'. The PCR product was purified using Gene JETTM PCR Purification Kit (Thermo K0701). The DNA sequencing of the PCR product was carried out by using Applied Biosystems (ABI) 3730xl DNA sequencer (GATC Biotech, Constance Germany) by using the above specific primers.

\subsection{Phylogenetic analysis}

The 16S-ribosomal DNA (rDNA) sequence of the Streptomyces strain (MA-St-1) was compared with the sequences available in National Center for Biotechnology Information (NCBI), GenBank database by using the Basic Local Alignment Search Tool (BLAST). The sequence was aligned together with those of reference taxa retrieved from public databases. The evolutionary distances were set up based on the parameter model and the phylogenetic tree was constructed by using the neighbor-joining method MEGA6 software [16] [38]. The 16S rDNA sequence was submitted to the NCBI Gene BankIt nucleotide sequence database under accession number MN795706.1.

\subsection{Ultraviolet (UV) mutagenesis}

The Streptomyces spores from old culture (3days) were suspended in sterile distilled water and the suspension was exposed to UV light for 15 minutes at $20 \mathrm{~cm}$ distance. After irradiation, the UV treated spore suspensions were shielded from light for 2 
hours. Suitable dilutions were spread on FM containing $1.5 \%$ of Locust chitin and incubated at $37^{\circ} \mathrm{C}$ for 3 days. The fast and large obtained colonies were cultured on tryptone soya agar (TSA) medium slants for the advanced assay of chitinase activities.

\subsection{Ethyl methanesulfonate (EMS) mutagenesis}

The Streptomyces spores from old culture (3 days) were suspended in sodium phosphate buffer $(0.1 \mathrm{M}, \mathrm{pH} 7.0)$ and treated with $200 \mathrm{mM}$ of EMS for 60 minutes. Suitable dilutions were spread on FM containing $1.5 \%$ of Locust chitin and incubated at $37{ }^{\circ} \mathrm{C}$ for 3 days. The fast and large obtained colonies were cultured on TSA medium slants for the advanced assay of chitinase activities.

\subsection{Chitinase activity measurement}

The enzyme solution $(0.5 \mathrm{ml}$ ), from FM after centrifugation at $8000 \mathrm{rpm}$ for $5 \mathrm{~min}$, was added to $1 \mathrm{ml}$ of $1.5 \%$ (w/v) colloidal chitin suspension of phosphate buffer $(50 \mathrm{mM}, \mathrm{pH} 7.0)$, then the mixture was incubated at $37^{\circ} \mathrm{C}$ for 10 minutes. The amount of reducing sugar formed in the supernatant after centrifugation at $8000 \mathrm{rpm}$ for $5 \mathrm{~min}$ was measured using the protocol designed by Imoto and Yagishita, using $\mathrm{N}$-acetylglucosamine as the reference substrate [13]. The activity of chitinase was determined by One unit of enzyme equal $1 \mu \mathrm{mol}$ of reducing sugar produced per minute.

\section{Isolation of total DNA from novel mutants}

The total DNA was isolated by using the DNA extraction Mini Kit (iNtRON Biotechnology Inc., South Korea). The quantity and purity of the extracted DNA were measured by calculating the UV-absorbance at 260nm and 280nm by a spectrophotometer (Shimadzu UV-VIS model UV-240, Shimadzu Scientific Instruments, Maryland, USA) [39].

\section{Molecular analysis of novel mutants}

The molecular analysis by PCR of the mutant was applied using 2x PCR Master Mix Solution (i-StarTaq), Hot-Start (iNtRON Biotechnology Inc., South Korea Product Catalog No: 25166). The 1x PCR Master Mix vials contain all essential components, unless primer and DNA template, for in vitro DNA amplification. The various primers applied in this work were obtained from Operon Technologies Inc, Venlo, Netherlands. The sequences for the three primers are: a first primer (P1) 5'CATACCCCCGCCGTT-3', second primer (P2) 5'-GTGTTGTGGTCCACT-3' and third primer (P4) 5'AACCTCCCCCTGACC-3'. Used random primer (12 ng) and purified DNA sample (40 ng) were added to each PCR bead. The total volume of the amplification cocktail was made to $25 \mu \mathrm{l}$ using the highly purified sterile distilled water. The amplification was performed as the following protocol; Denaturation of double stranded DNA at $95^{\circ} \mathrm{C}$ for 1 minutes. Primer annealing to template DNA for $1.5 \mathrm{~min}$ according to $\mathrm{GC}$ ratio of each primer. Extension-DNA polymerization by incubation at $72^{\circ} \mathrm{C}$ for 1 minutes. These three steps were repeated 35 times. At the end, PCR was kept at hold at $4^{\circ} \mathrm{C}$. The amplified DNA products were separated based on size through gel electrophoresis. These DNA products were loaded into precast wells on $1.0 \%$ agarose gel and $1 \mathrm{X}$ Tris/Borate/EDTA (TBE) buffer and current of consistent 100 volts was applied for about 2 hours. The different separate bands were detected against the 100 base pair (bp) ladder (iNtRON Biotechnology Inc., South Korea). The separated bands were stained with $0.5 \mu \mathrm{g} / \mathrm{ml}$ ethidium bromide and photographed using Gel Documentation System with a UVtransilluminator.

\section{RESULTS AND DISCUSSION}

\section{Screening for extracellular chitinase production of chitinolytic actinomycetes}

Screening for extracellular chitinase production of different isolates from rhizosphere and after mutagenesis was done to choose the best strains for chitinase production. After isolation of the large numbers of strains that grow well at the FM containing $1.5 \%$ of Locust chitin (Figure 1), four excellent isolates were selected to evaluate the chitinase production. (Table 1) presented the effect of three different incubation periods (2, 4 and 6 days) on chitinase productivity of the four excellent Streptomyces isolates obtained after isolation and screening on FM containing $1.5 \%$ of Locust chitin. Data in (Table 1) clearly showed that the 4 days incubation period proved to be the best one since the all tested strains produced higher amounts of chitinase production during this incubation period. The highest records of chitinase productivity were 4.9 Units. $\mathrm{mL}^{-1}$ which were obtained from the original strain Streptomyces (MA-St-1) for 4 days. The following strain of chitinase productivity was strain MA-St-2. On the other hand, the lowest record of chitinase production following 2 days of incubation was 2.1 Units. $\mathrm{mL}^{-1}$ which was obtained from the strain Streptomyces (MA-St-4). Investigations using Streptomyces sp. exhibited maximum of chitinase activity after 6 days of incubation and declined thereafter, which is not harmonic with our observations [36]. 


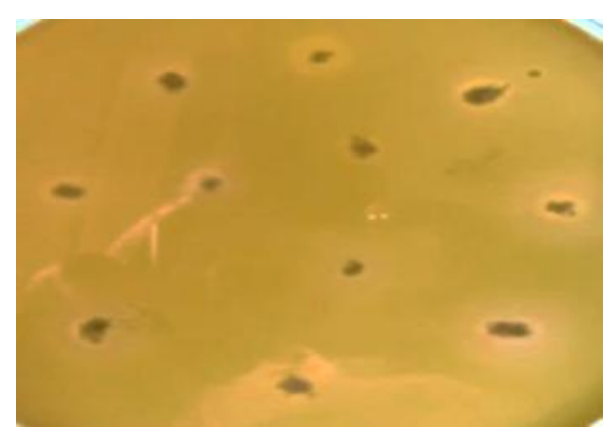

Fig. 1: Screening assay using FM containing $1.5 \%$ of Locust chitin to detect chitinase producing soil isolates obtained from different places of Jeddah, KSA.

From the foregoing results out of the four tested strains, Streptomyces (MA-St-1) proved to be the highest chitinase producer in comparison with the other tested strains. So, it was selected to be the parental strain for all of the following genetic techniques to improve chitinase production.

Table 1: Chitinase production of the original strains cultured in FM medium under different incubation times

\begin{tabular}{|c|c|c|c|}
\hline \multirow{2}{*}{ Strain code No. } & \multicolumn{3}{|c|}{ FM } \\
\cline { 2 - 4 } & $\mathbf{2 d *}$ & $\mathbf{4 d}$ & $\mathbf{6 d}$ \\
\hline MA-St-1 & $3.4^{* *}$ & 4.9 & 4.8 \\
\hline MA-St-2 & 3.2 & 3.5 & 3.4 \\
\hline MA-St-3 & 2.4 & 3.2 & 3.2 \\
\hline MA-St-4 & 2.1 & 2.8 & 2.7 \\
\hline
\end{tabular}

$* \mathrm{~d}=$ days, $* *$ Units. $\mathrm{mL}^{-1}$

\section{Molecular identification of Streptomyces strain (MA-St-1)}

To identify the precise name of the isolated strain (MA-St-1), 16S-rRNA gene investigation was performed. The 16S specific primers were applied to obtain the fragment of the 16S-ribosomal ribonucleic acid (rRNA) gene from the total DNA of the Streptomyces (MA-St-1). After the amplification by PCR, a product of nearly 1500 bp was detected (Figure 2). The BLAST analysis of the amplified 16S rRNA gene sequence revealed 99\% resemblance to the partial 16S-rRNA gene of Streptomyces halstedii (NR_044148.1) strain. Based on this resemblance, the Streptomyces (MA-St-1) was identified as Streptomyces halstedii (Figure 3).

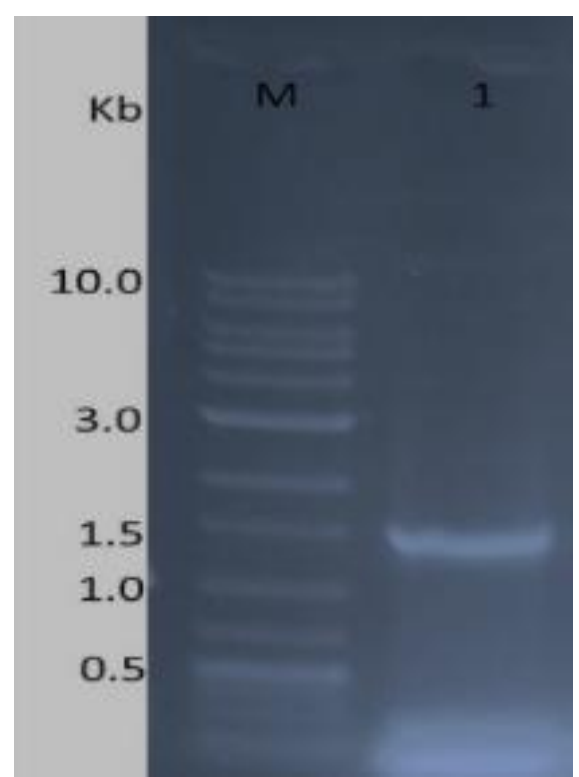

Fig. 2: Photograph of 16S-DNA amplified band for Streptomyces (MA-St-1) (lane 1) using 16S forward and reverse primers against ladder DNA marker, iNtRON Biotechnology Inc., South Korea, (lane M) 


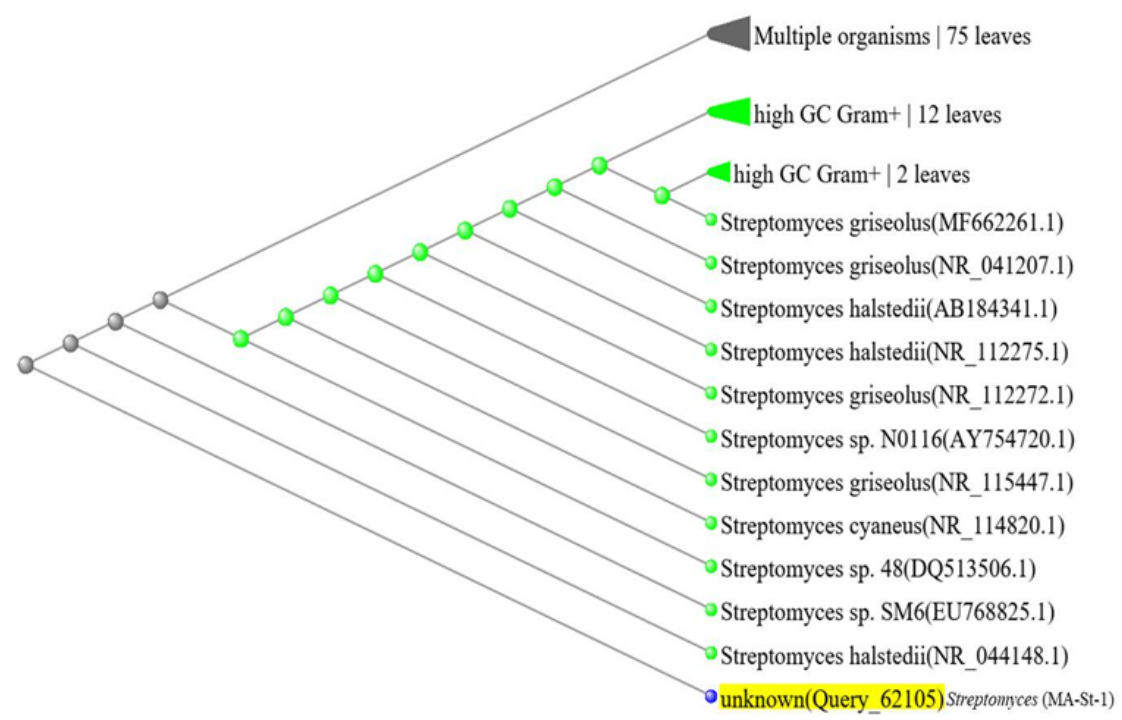

Fig. 3: Phylogenetic tree based on the 16S-rRNA gene sequence of the efficient Streptomyces (MA-St-1) producing chitinase from Locust chitin in comparison to the most related bacterial strain (Streptomyces halstedii) in NCBI GenBank database

\section{Optimization of chitinase synthesis by the S. halstedii MA-St-1 strain Different concentration of Locust chitin}

Different concentrations of Locust chitin $(0.25$ to $2 \%)$ were evaluated for their role in chitinase productivity by parental strain

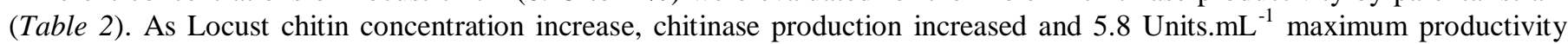
from parental strain were observed at $1 \%(\mathrm{w} / \mathrm{v})$ Locust chitin then the chitinase production was decreased. [20] exhibited that among all the concentrations, $0.2 \%$ chitin showed the optimum production of chitinase $(0.38 \mathrm{U} / \mathrm{mg})$. On the other hand, [43] proved the increased production was possible using the increased concentrations of chitin. According to [10], S. viridificans gave high amounts of chitinase in a modified medium containing $1.5 \%$ of chitin after 6 days of fermentation at $30^{\circ} \mathrm{C}$.

\section{Temperature degrees}

(Table 3) describes the action of different temperatures on chitinase production. Temperature influenced chitinase production and the optimum temperature to maximize chitinase production for the parental strain was $35^{\circ} \mathrm{C}$. Kolla and Vijayalakshmi, notified that the Streptomyces Anu 6277 exhibited its optimum growth at temperature $35^{\circ} \mathrm{C}$ [19]. Kotra et al., observed that the highest chitinase production was obtained at $28^{\circ} \mathrm{C}$ [20]. On the other hand, a high level of observed chitinase activity in the production medium with a temperature $30^{\circ} \mathrm{C}$ was obtained [14]. Furthermore, the optimum obtained chitinase production after $3^{\text {rd }}$ day of incubation, at temperature $40^{\circ} \mathrm{C}$, was found [42]. In general, the optimum temperatures for chitinase production by Streptomyces sp. were lies between $30^{\circ} \mathrm{C}$ to $40^{\circ} \mathrm{C}$ [9] [41].

Table 2: Influence of Locust chitin concentration on chitinase productivity by S. halstedii MA-St-1 strain

\begin{tabular}{|c|c|}
\hline Locust chitin conc. $(\%)$ & Chitinase $\left(\mathbf{U . m L}^{-1}\right)$ \\
\hline 0.25 & 3.1 \\
\hline 0.5 & 4.9 \\
\hline 0.75 & 5.6 \\
\hline 1.0 & 5.8 \\
\hline 1.25 & 4.0 \\
\hline 1.5 & 3.2 \\
\hline 2.0 & 2.5 \\
\hline
\end{tabular}

Table 3: Influence of temperature on chitinase productivity by $S$. halstedii MA-St-1 strain

\begin{tabular}{|c|c|}
\hline Temperature $^{\mathbf{0}} \mathbf{C}$ & Chitinase $\left(\mathbf{U . m L}^{\mathbf{1}}\right)$ \\
\hline 30 & 4.9 \\
\hline 35 & 5.6 \\
\hline 40 & 5.2 \\
\hline 45 & 3.5 \\
\hline 50 & 1.2 \\
\hline
\end{tabular}

\section{Different pH values}

(Table 4) presented the Influence of different $\mathrm{pH}$ values on chitinase production. Chitinase production showed a significant increase (5.8 Units. $\mathrm{mL}^{-1}$ ) for parental strain when the $\mathrm{pH}$ value increased from 7.0 to 9 . Most of the chitinase production through fermentation is carried out between $\mathrm{pH} 6$ and 10 and it varies from genus to genus [11] [1] [42]. 
Table 4: Influence of $\mathrm{pH}$ on chitinase productivity by S. halstedii MA-St-1 strain

\begin{tabular}{|c|c|}
\hline $\mathbf{p H}$ & Chitinase $\left(\mathbf{U}_{\mathbf{m}} \mathbf{m L}^{-\mathbf{1}}\right)$ \\
\hline 7 & 4.9 \\
\hline 7.5 & 5.2 \\
\hline 8.0 & 5.8 \\
\hline 8.5 & 5.3 \\
\hline 9.0 & 2.6 \\
\hline
\end{tabular}

\section{Different carbon substrates}

The carbon source is a critical substrate in the fermentation medium for the chitinase production. Thus, various carbon sources were tested for chitinase production as shown in (Table 5). Mostly, carbon sources appeared to be more appropriate for the synthesis of chitinase. Among all the tested carbon sources, xylose was found to be more suitable for high yield of chitinase production of parental strain followed by glucose (5.6 and 5.3 Units. $\mathrm{mL}^{-1}$, respectively).

This result is an opposite with the observation of [19] they reported that, among the various carbon sources, chitinase production was the highest when starch was used followed by cellulose.

\section{Different nitrogen sources}

Between the sources of tested organic nitrogen, peptone was found to be more suitable for high yield of chitinase production of parental strain followed by yeast extract (5.7 and 4.9 Units. $\mathrm{mL}^{-1}$, respectively), as shown on (Table 6). In our work, the addition of ammonium nitrate, sodium nitrate and potassium nitrate to the fermentation medium had no effect on the production of chitinase. However, the addition of peptone and yeast extract in the fermentation medium significantly affected the production of chitinase by Streptomyces halstedii MA-St-1. In Streptomyces sp., [33] reported that decreased yeast extract and ammonium sulfate concentrations may promote chitinase production [33]. Also, [19] reported that, among the various nitrogen sources, chitinase production was the highest when yeast extract $(0.4 \%)$ was used followed by Soybean meal $(0.6 \%)$.

Table 5: Influence of additional carbon source on chitinase productivity by S. halstedii MA-St-1 strain

\begin{tabular}{|c|c|}
\hline Carbon source $(\mathbf{0 . 1 \%}, \mathbf{w} / \mathbf{v})$ & Chitinase (U.mL $\left.\mathbf{~}^{-1}\right)$ \\
\hline without & 4.9 \\
\hline Glucose & 5.3 \\
\hline Galactose & 3.7 \\
\hline Fructose & 4.1 \\
\hline Xylose & 5.6 \\
\hline Sucrose & 5.2 \\
\hline Lactose & 3.8 \\
\hline Carboxymethyl cellulose & 5.2 \\
\hline Xylan & 5.1 \\
\hline
\end{tabular}

Table 6: Influence of nitrogen source on chitinase productivity by $S$. halstedii MA-St-1 strain

\begin{tabular}{|c|c|}
\hline Nitrogen source $(\mathbf{0 . 5 \%}, \mathbf{w} / \mathbf{v})$ & Chitinase $\left(\mathbf{U}_{\mathbf{m}} \mathbf{m L}^{\mathbf{- 1}}\right)$ \\
\hline Yeast extract & 4.9 \\
\hline Peptone & 5.7 \\
\hline Meat extract & 4.5 \\
\hline Beef extract & 4.3 \\
\hline Ammonium nitrate & 3.5 \\
\hline Sodium nitrate & 4.6 \\
\hline Potassium nitrate & 3.7 \\
\hline
\end{tabular}

\section{Mutagenesis and chitinase productivity}

Mainly the mutation induces a modification in DNA nucleotide sequences, after the induction of mutations using some agents that react with DNA. Naturally genetic variations occur are known to be infrequent in comparison with the generated genetic variations, a DNA sequence variations such as base-pair substitution, insertion, deletion is randomly occur in the microbial genome by applications of physical and chemical mutagenic agents. To improve of the Streptomyces genomes, the universal agents such as ultraviolet light (UV) and alkyl agents (EMS and NTG), which normally induce several mutations in the Streptomyces DNA, are applied. EMS induces C-T variants resulting in C/G and T/A substitutions. Also, the 7-ethyl- guanidine produced by EMS hydrolysis results in $\mathrm{G} / \mathrm{C}$ to $\mathrm{C} / \mathrm{G}$ or $\mathrm{G} / \mathrm{C}$ to $\mathrm{T} / \mathrm{A}$ trans-versions while 3-ethyl-adenine pairing errors cause $\mathrm{A} / \mathrm{T}$ to $\mathrm{G} / \mathrm{C}$ transitions [22] [21] [18]. To extensively promote the enzyme productivity at the industrial level, the mutant strains are used.

The superior chitinase-producing original strain was mutated by UV and EMS mutagens. The Streptomyces spores were treated with UV rays and EMS mutagen $(200 \mathrm{mM})$. The treated spores suspension was then diluted and spread onto the surface of the 
FM medium with and without $1.5 \%$ of Locust chitin and incubated at $37{ }^{\circ} \mathrm{C}$ for 3 days to select thermotolerant and highly chitinase producers colonies. The colonies with a high growth rate were transferred on slants for further experiments. The resistant mutants with a high growth rate were re-cultured on the same medium plates to confirm their resistance. It was exhibited that the count of original strains before and after mutagenesis with each mutagen. Also, the mutants in which thermotolerant and high growth at $1.5 \%$ of Locust chitin were counted after mutagenesis with each mutagen (Table 1). Furthermore, the survival percentages were decreased after mutagenesis with each mutagen and reached to 10.68 and $8.41 \%$ after 15 and 60 min of UV and EMS-treatments, respectively. Furthermore, from about the 122 survival colonies obtained after UV-treatment 25 mutants showed a thermotolerant and high growth at $1.5 \%$ of Locust chitin.

On the other hand, from about the 96 survival colonies obtained after EMS-treatment 19 mutants showed a thermotolerant and high growth at $1.5 \%$ of Locust chitin. The reduction in survival after 15 and 60 min of UV and EMS-mutagenesis could be ascribed to the DNA damage and/or losses some of the cell components due to mutagens used. The above results were agreement with those obtained by [6] [35].

The 25-mutants were assayed by growing these mutants in the FM medium for 4 days, to detect the effect of the UV mutagenesis on chitinase production. (Table 2) observed that the parental strain (wild type) gave 5.7 U.mL ${ }^{-1}$, only two mutants of them showed chitinase at the same production level by the parental wild type, 21 mutants of them exhibited chitinase produced more than the parental strain. These results specified that the majority of the tested mutants gave chitinase higher than their parental strain. The highest chitinase producer mutant was UV/15-15 since it showed 189.47 percent production higher than the parental wild type strain. The following superior mutant for chitinase productivity was UV/15-12 which produced $10.6 \mathrm{U}^{-\mathrm{mL}^{-1}} \mathrm{or}^{185.96}$ percent production higher than the parental wild type strain. Meanwhile, two mutants, i.e., UV/15-8 and UV/15-18 proved to have a little bit less efficiency chitinase productivity than the parental wild type strain.

Moreover, when tested the nineteen of chitinase producers mutants obtained after 60 min. of EMS-mutagenesis for chitinase production (Table 3), no one of mutants showed chitinase at the same produced by the parental wild type strain, 16 mutants of them showed chitinase produced more than the parental wild type strain. These results also specified that many of the tested mutants gave chitinase higher than their parental wild type strain. The highest chitinase producer mutant was E/60-12 since it showed 207.02 percent production higher than the parental wild type strain. The following superior mutant for chitinase productivity was E/60-6 which produced $11.3 \mathrm{U} \cdot \mathrm{mL}^{-1}$ or 198.25 percent production higher than the parental wild type strain. And finally, only three mutants proved to have a little bit less efficiency chitinase productivity than the parental wild type strain.

The same trends results were obtained with [46]. They mutagenized Streptomyces peucetius with NTG-mutagen and isolated the mutant (SPVI) which flopped down to produce daunorubicin but at the same time overproduction of chitinase. The obtained results agreed also with those [23]. He developed two UV-mutants (SGUV5 and SGUV30) from Streptomyces griseoaurantiacus with $12.8 \%$ and 57.4\% higher activities of $\beta$-glucosidase and endoglucanase, respectively. [5] employed random mutagenesis (UV and Ethyl methanesulfonate) to increase the production of fibrinolytic enzymes by Streptomyces venezuelae and obtained Mutant (EMS3) which gave fibrinolytic activity of $13 \mathrm{FU} / \mathrm{mL}$ in comparison with the wild strain (6 FU/mL). [2] improved chitinase production by Bacillus pumilus CHT11 using UV-mutagenesis. The UV-treatments induced mutants with higher chitinase production as well as biocontrol activity against some pathogenic fungi compared to the wild isolate. Mutant BM33 showed a higher chitinase production rate (5 fold increasing) more than the wild type. Moreover, [32] treated of Bacillus subtilis by the chemical mutagen ethyl methanesulfonate (EMS) to improve 3 mycolytic enzymes (chitinase, $\beta$-1,3-glucanase, and cellulase). The superior mutant B. subtilis M59 showed a high level of mycolytic enzyme production and enzyme-mediated suppression of the fungal pathogens growth in comparison with the wild type strain and other B. subtilis mutants. Furthermore, the strain development for hyper-production of extracellular chitinase enzyme using Pseudomonas stutzeri is achieved by N-methyl-N'-nitro-N-nitrosoguanidine (NTG) treatment or UV radiation according to [24]. They obtained the excellent mutants (P. stutzeri YPL-M26 and YPL-M178) which gave larger inhibition zones after UV and NTGmutagenesis. This is due to increased antifungal activities of chitinase and laminarinase. Also, [25] elevated tylosin productivity by $S$. fradiae using standard UV and EMS- treatments and recombinant protoplast fusion method.

Table 7: Effect of UV and EMS mutagens S. halstedii MA-St-1 spores' survival

\begin{tabular}{|c|c|c|c|c|}
\hline \multirow[t]{2}{*}{$\begin{array}{c}\text { Exposure time (min.) and } \\
\text { mutagens }\end{array}$} & \multicolumn{2}{|c|}{$\begin{array}{c}\text { No. of viable colonies and } \\
\%\end{array}$} & \multicolumn{2}{|c|}{$\begin{array}{c}\text { Thermotolerant mutants grown at } 37^{\circ} \mathrm{C} \text { and } 1.5 \% \text { locust } \\
\text { chitin }\end{array}$} \\
\hline & No. & $\%$ & No. & $\%$ \\
\hline 0 & 1142 & 100.00 & $3 *$ & 0.26 \\
\hline $15 \mathrm{UV}$ & 122 & 10.68 & 25 & 20.49 \\
\hline 60 EMS & 96 & 8.41 & 19 & 19.79 \\
\hline
\end{tabular}

*Very petite colonies

Table 8: Chitinase productivity of resistant mutants after mutagenesis of $S$. halstedii MA-St-1 with UV-light for 15min

\begin{tabular}{|c|c|c|c|c|c|}
\hline Strain No. & Chitinase (U.mL $\left.{ }^{-1}\right)$ & $\%$ to $\mathrm{W} . \mathrm{T}$ & Strain No. & Chitinase (U.mL $\left.{ }^{-1}\right)$ & $\%$ to $\mathrm{W} . \mathrm{T}$ \\
\hline MA-St-1 (W.T) & 5.7 & 100.00 & UV/15-13 & 8.3 & 145.61 \\
\hline $\mathrm{UV} / 15-1$ & 8.2 & 143.86 & UV/15-14 & 6.4 & 112.28 \\
\hline $\mathrm{UV} / 15-2$ & 5.7 & 100.00 & UV/15-15 & 10.8 & 189.47 \\
\hline $\mathrm{UV} / 15-3$ & 7.4 & 129.82 & UV/15-16 & 7.5 & 131.58 \\
\hline $\mathrm{UV} / 15-4$ & 6.7 & 117.54 & UV/15-17 & 5.8 & 101.75 \\
\hline
\end{tabular}


Citation: Manal E. Shafi. and Abd El-Nasser A. Khattab, Improvement of Chitinase produced from Chitin of Desert Locust by Streptomyces halstedii strain Isolated from Jeddah, KSA. Advances in Environmental Biology, 14(1): 7-18. DOI:10.22587/aeb.2020.14.1.2

\begin{tabular}{|c|c|c|c|c|c|}
\hline $\mathrm{UV} / 15-5$ & 8.5 & 149.12 & $\mathrm{UV} / 15-18$ & 4.5 & 78.95 \\
\hline $\mathrm{UV} / 15-6$ & 10.2 & 178.95 & $\mathrm{UV} / 15-19$ & 10.3 & 180.70 \\
\hline $\mathrm{UV} / 15-7$ & 8.9 & 156.14 & $\mathrm{UV} / 15-20$ & 6.8 & 119.30 \\
\hline $\mathrm{UV} / 15-8$ & 5.3 & 92.98 & $\mathrm{UV} / 15-21$ & 7.7 & 135.09 \\
\hline $\mathrm{UV} / 15-9$ & 9.2 & 161.40 & $\mathrm{UV} / 15-22$ & 9.5 & 166.67 \\
\hline $\mathrm{UV} / 15-10$ & 6.7 & 117.54 & $\mathrm{UV} / 15-23$ & 6.7 & 117.54 \\
\hline $\mathrm{UV} / 15-11$ & 5.8 & 101.75 & $\mathrm{UV} / 15-24$ & 5.7 & 100.00 \\
\hline $\mathrm{UV} / 15-12$ & 10.6 & 185.96 & $\mathrm{UV} / 15-25$ & 8.3 & 145.61 \\
\hline
\end{tabular}

Table 9: Chitinase productivity of resistant mutants after mutagenesis of $S$. halstedii MA-St-1 with EMS for 60 min

\begin{tabular}{|c|c|c|c|c|c|}
\hline Strain No. & Chitinase (U.mL $\left.{ }^{-1}\right)$ & $\%$ to $\mathrm{W} . \mathrm{T}$ & Strain No. & Chitinase (U.mL $\left.{ }^{-1}\right)$ & \% to $\mathrm{W} . \mathrm{T}$ \\
\hline MA-St-1 (W.T) & 5.7 & 100.00 & $\mathrm{E} / 60-10$ & 9.5 & 166.67 \\
\hline $\mathrm{E} / 60-1$ & 6.2 & 108.77 & $\mathrm{E} / 60-11$ & 6.4 & 112.28 \\
\hline $\mathrm{E} / 60-2$ & 5.8 & 101.75 & $\mathrm{E} / 60-12$ & 11.8 & 207.02 \\
\hline $\mathrm{E} / 60-3$ & 6.3 & 110.53 & $\mathrm{E} / 60-13$ & 10.4 & 182.46 \\
\hline $\mathrm{E} / 60-4$ & 8.6 & 150.88 & $\mathrm{E} / 60-14$ & 9.6 & 168.42 \\
\hline $\mathrm{E} / 60-5$ & 4.7 & 82.46 & $\mathrm{E} / 60-15$ & 7.3 & 128.07 \\
\hline E/60-6 & 11.3 & 198.25 & $\mathrm{E} / 60-16$ & 5.6 & 98.25 \\
\hline $\mathrm{E} / 60-7$ & 5.6 & 98.25 & $\mathrm{E} / 60-17$ & 8.2 & 143.86 \\
\hline $\mathrm{E} / 60-8$ & 10.0 & 175.44 & $\mathrm{E} / 60-18$ & 7.8 & 136.84 \\
\hline E/60-9 & 8.4 & 147.37 & $\mathrm{E} / 60-19$ & 6.1 & 107.02 \\
\hline
\end{tabular}

\section{Characterization of the novel superior mutants by RAPD assay}

Three RAPD primers and three tested UV and EMS-mutants as well as Streptomyces halstedii MA-St-1 (parental) were used to exhibit the molecular changes after different mutagenic treatments. The obtained banding patterns after RAPD assay of the tested mutants and parental wild type strain when the RAPD primer (P1) was applied as shown in (Figure 4) Five bands (1400, $1200,900,800,400 \mathrm{bp}$ ) were detected for the parental wild type strain (lane 1). Also, the same band's number was detected for the E/60-12 mutant (lane 4) but with new two bands (1000, 350bp). The mutant UV/15-15 (lane 2) has the lowest band number (4 bands) but with new two bands $(1000,350 \mathrm{bp})$. Furthermore, the mutant E/60-6 (lane 3) has the highest bands number (6 bands) and gave three new bands $(1000,650,350 \mathrm{bp})$ in comparison with the parental wild type strain.

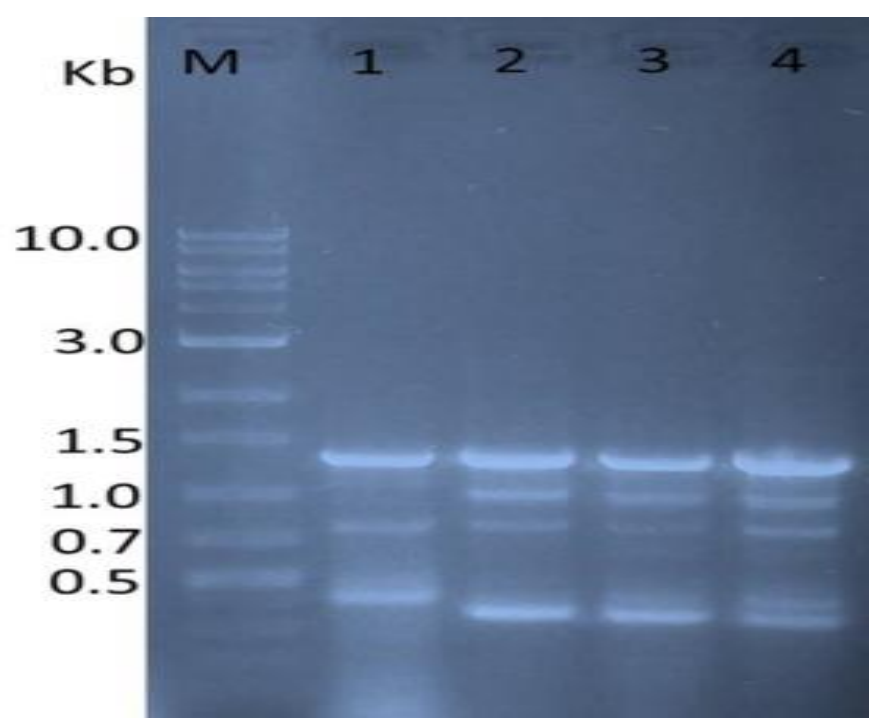

Fig. 4: RAPD-DNA obtained banding patterns by a primer (P1) for three superior mutants (Lanes 2 to 4 ) and Streptomyces halstedii MA-St-1 parental wild type strain (lane 1) opposite to Sizer ${ }^{\mathrm{TM}}-1000$ plus DNA Marker (lane M). The tested mutants sequence as follows: UV/15-15, E/60-6 and E/60-12

Moreover, using P2 primer (Figure 5) with the tested mutants in comparison of S. halstedii MA-St-1 parental wild type strain. All the detected amplified bands (13 bands) were faint or very faint in all of the tested mutants and the parental wild type strain. The only exception, the two monomorphic bands (1600, 350bp) gave a distinctive form. Six bands $(1600,1500,1000,800,350$, 200bp) were detected for the parental strain (lane 1). The mutant UV/15-15 (lane 2) has the lowest band number (4 bands) but with a new polymorphic band (1400bp). Furthermore, the mutant E/60-12 (lane 4) has the highest band number (10 bands) and gave two unique bands $(700,500 \mathrm{bp})$ and three new polymorphic bands $(1400,900,300 \mathrm{bp})$ compared to the parental strain. And finally, the mutant E/60-6 (lane 3) has the bands number (9 bands) and gave five new polymorphic bands (2000, 1400, 900, 600, $300 \mathrm{bp}$ ) in comparison with the parental wild type strain. 


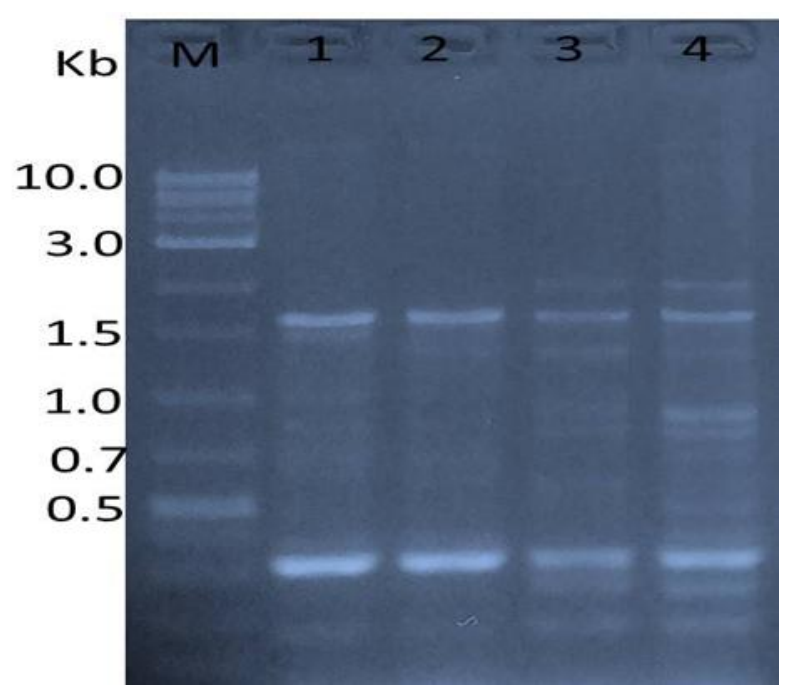

Fig. 5: RAPD-DNA obtained banding patterns by a primer (P2) for three superior mutants (Lanes 2 to 4 ) and Streptomyces halstedii MA-St-1 parental wild type strain (lane 1) opposite to Sizer ${ }^{\mathrm{TM}}-1000$ plus DNA Marker (lane M). The tested mutants sequence as follows: UV/15-15, E/60-6 and E/60-12

The molecular typing by $\mathrm{P} 4$ primer with the tested mutants compared to parental S. halstedii MA-St-1 strain (Figure 6), the parental wild type strain (lane 1) gave five bands of molecular weights $(1250,1000,600,490,400 \mathrm{bp})$. The mutant strain UV/15-15 (lane 2) gave a new one polymorphic band (150 bp) beside the same number of bands which detected in the parental wild type strain. The mutant strain E/60-6 (lane 3) gave only two new bands (1200 and $150 \mathrm{bp}$ ). The mutant strain E/60-12 (lane 4) has the highest band number ( 7 bands) and gave one unique band (850bp) and one new polymorphic band (150bp) in comparison with the parental wild type strain.

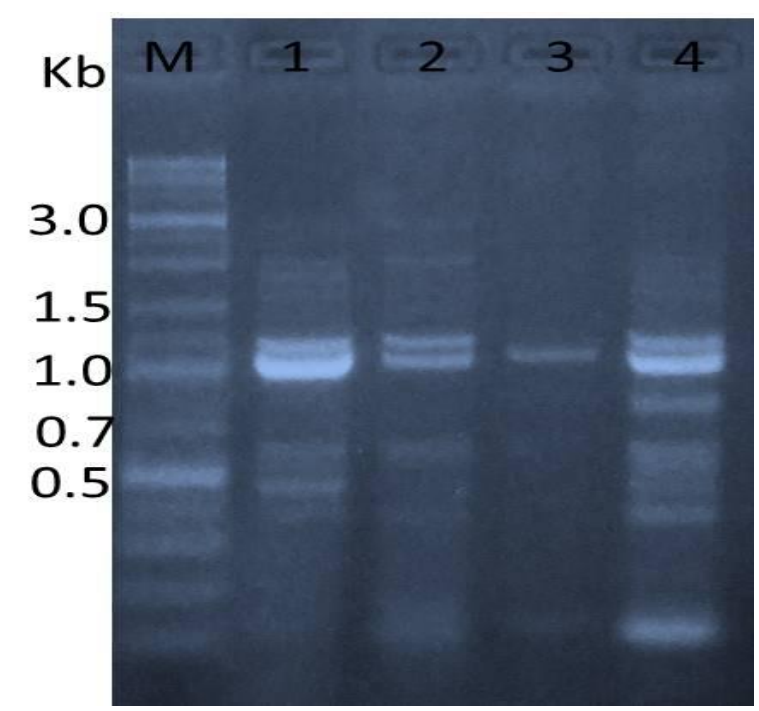

Fig. 6: RAPD-DNA obtained banding patterns by a primer (P4) for three superior mutants (Lanes 2 to 4 ) and Streptomyces halstedii MA-St-1 parental wild type strain (lane 1) opposite to Sizer ${ }^{\mathrm{TM}}-1000$ plus DNA Marker (lane M). The tested mutants sequence as follows: UV/15-15, E/60-6, and E/60-12

The number of the obtained banding patterns after RAPD assay as shown in (Table 10) when used the primer P1 were 8 bands, primer P2 were 13 bands, primer P3 were 8 bands. Furthermore, the elevated polymorphic bands were obtained with the primer P2 and the minimized polymorphic bands were observed with the primer P1. Moreover, the minimized unique bands were detected with the primer P3 and the elevated unique bands were detected with the primer P2. Three unique bands obtained after used the primer P1. Also, when used the primer P1 and primer P2, the obtained monomorphic bands are the same number (two bands) and no monomorphic bands exhibited after the primer P3 was applied.

Table 10: Different amplified DNA bands, as well as the percentages of polymorphic bands, obtained using the applied primers Primer code Total band No. Monomorphic band No. Unique band No.Polymorphic band No.Polymorphic percentage

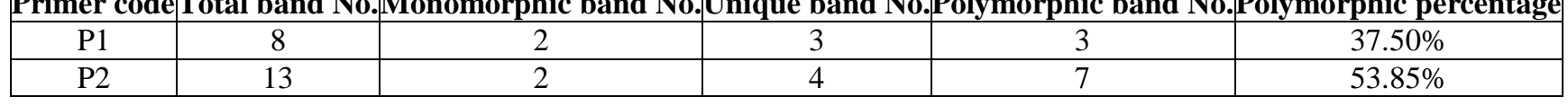


Citation: Manal E. Shafi. and Abd El-Nasser A. Khattab, Improvement of Chitinase produced from Chitin of Desert Locust by Streptomyces halstedii strain Isolated from Jeddah, KSA. Advances in Environmental Biology, 14(1): 7-18. DOI:10.22587/aeb.2020.14.1.2

\begin{tabular}{|c|c|c|c|c|c|}
\hline P4 & 8 & 0 & 2 & 6 & $75.00 \%$ \\
\hline Total & 29 & 4 & 9 & 16 & - \\
\hline
\end{tabular}

The changes obtained in DNA nucleotides must have variation in RAPD banding patterns (fingerprints). The changes of nucleotides at the annealing nucleotides sequences of the primer may prevent the annealing and can be observed in the loss of the identical amplified band. Also, the new annealing sites can appear in the template (genome) through mutations, thus producing the new bands. Various investigations using RAPD assays to detect of Streptomyces strains and mutants diversities [27] [48] [40] [6] [35].

\section{Phylogenetic tree and distance through RAPD method}

To obtain the precise relationships between the obtained different banding patterns according to the PCR-RAPD data, the genetic distances were done (Table 11). The elevated genetic distance was detected between UV/15-15 and E/60-12 (72.7\%) followed by $(72.2 \%)$ between E/60-6 and E/60-12. On the other hand, the minimized genetic distance matrix (40.0\%) was obtained between E/60-6 and the parental strain.

According to the phylogenetic tree, as shown in (Figure 7), the dendrogram through RAPD distances exhibited that the mutants UV/15-15 and E/60-12 grouped into one first cluster and this cluster was attached with mutant E/60-6 in the second cluster. Moreover, the profoundly different parental strain linked with the first and second clusters in the third cluster. The separation of the novel superior mutants and the parental strain into different groups could be used to reflect the genetic diversities of the superior chitinase producer mutants. Moreover, (Figure 7) observed that the novel genotypes (mutants UV/15-15 and E/60-12) which postulated to be elevated chitinase producer were closed together in one cluster. The above results are the same trend as those exhibited by [18] [35].

Table 11: Proximity matrix within the novel's mutants concerning the parental S. halstedii MA-St-1 strain based on the RAPD method

\begin{tabular}{|c|c|c|c|c|}
\hline Strain code & Parental strain & UV/15-15 & E/60-6 & E/60-12 \\
\hline Parental strain & 1.000 & 0.519 & 0.400 & 0.556 \\
\hline UV/15-15 & 0.519 & 1.000 & 0.593 & 0.727 \\
\hline E/60-6 & 0.400 & 0.593 & 1.000 & 0.722 \\
\hline E/60-12 & 0.556 & 0.727 & 0.722 & 1.000 \\
\hline
\end{tabular}

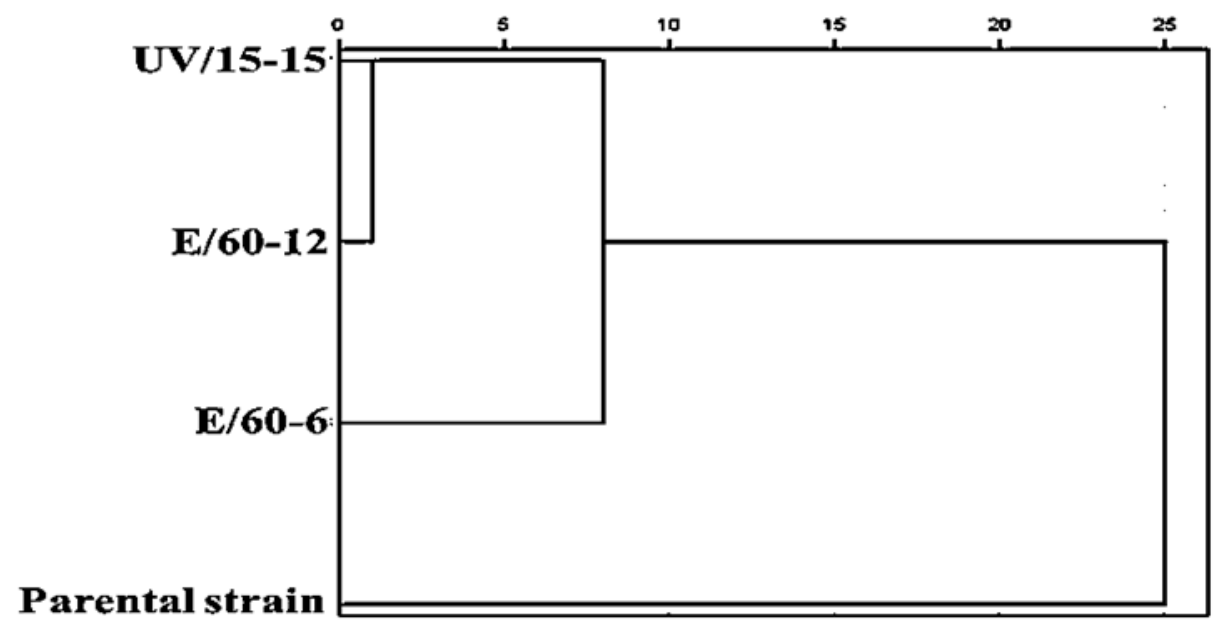

Fig. 7: Phylogenetic tree and distance via Average Linkage dendrogram of three novel mutants in comparison with parental $S$. halstedii MA-St-1 strain through RAPD method

\section{CONCLUSION}

These studies have revealed that an improvement of chitinase productivity by Streptomyces halstedii isolated from Jeddah, KSA, after optimization of the fermentation process, was obtained through UV and EMS-mutagenesis. Moreover, changes in some outstanding mutants RAPD patterns in comparison with the parental wild type strain were exhibited and at the same time, these changes proved as an indicator of genetic diversities of $S$. halstedii superior mutants. The division of the tested mutants into clusters through the phylogenetic program was applied and reflects the high genetic variabilities of some superior chitinase mutants.

\section{ACKNOWLEDGEMENT}




\section{CONFLICT OF INTEREST}

The authors declare that there is no conflict of interest

\section{REFERENCES}

[1] Abdulkhair, W. M. (2012). Chitinolytic activity of highly halotolerant Streptomyces tendae against Fusarium oxysporum PTK2. Afr. J. Biotechnol., 11: 15523-15532.

[2] Aly M. M., S. Tork and S. Y. Alakilli (2011). Molecular characterization of chitiniolytic Bacillus pumilus isolated from marine habitats and enhancement of chitinase production by mutation. Universal Scholars Biotechnol., 1: 14-21.

[3] Apichaisataienchote B., J. Altenbuchner, H. Buchenauer (2005). Isolation and identification of Streptomyces fradiae SU-1 from Thailand and protoplast transformation with the chitinase B gene from OPC-131. Curr. Microbiol., 51: 116-121.

[4] Berger L.R., D.M. Reynolds (1958). The chitinase system of a strain of Streptomyces griseus. Biochim. Biophys. Acta, 29: $522-534$.

[5] Bhavani B., B. Naveena, N. Partha (2012). Strain improvement of Streptomyces venezuelae for enhanced fibrinolytic enzyme production. Adv. Mat. Res., 584: 440-444.

[6] El-Sherbini A., A.A. Khattab (2018). Induction of novel mutants of Streptomyces lincolnensis with high lincomycin production. J. Appl. Pharm. Sci., 8: 128-135.

[7] FAO (2014). Desert Locust situation update.

[8] Gohel V., A. Singh, M. Vimal, P. Ashwini, H.S. Chhatapar (2006). Review: Bioprospecting and antifungal potential of chitinolytic microorganisms. Afr. J. Biotechnol., 5:54-72.

[9] Gomes R.C., L.T. Semedo, R.M. Soares, L.F. Linhares, C.J. Ulhoa, C.S. Alviano, R.R. Coelho (2001). Purification of a thermostable endochitinase from Streptomyces RC1071 isolated from a Cerrado soil and its antagonism against phytopathogenic fungi. J. Appl. Microbiol. 90 (4): 653-661.

[10] Gupta, R., R.K. Saxena, P. Chaturvedi, J.S. Viridi, (1995). Chitinase production by Streptomyces viridificans: its potential in fungal cell wall lysis. J. Appl. Bacteriol., 78, 378-383.

[11] Hara, S., Y. Yamamura, Y. Fyjii, T. Mega, T. Ikenaka (1989). Purifcation and characterization of chitin as produced by Streptomyces erythraeus. J. Biochem., 105: 484-489.

[12] Imoto T. and K. Yagishita (1971). A simple activity measurement by lysozyme. Agric. Biol. Chem., 35:1154-1156.

[13] Imoto T., K. Yagishita (1971). A simple activity measurement of lysozyme. Agric. Biol. Chem., 35: 1154-1156.

[14] Jagadeeswari S. and K. Panneer (2012). Optimization of Chitinase production by soil Streptomyces sp. SJKP9. J. Acad. Indus. Res., 1(6): 332-336.

[15] Jeuniaux C. (1966). Chitinases. Meth. Enzymol., 8: 644-650.

[16] Jukes T.H., C.R. Cantor (1969). Evolution of protein molecules, pp. 21-132 in Munro HN (ed.) Mammalian protein metabolism. Academic Press, New York.

[17] Kaya M., K.Ö. Tozak, T. Baran, G. Sezen, I. Sargın (2013). Natural porous and nano fiber chitin structure from Gammarus argaeus (Gammaridae Crustacea). Excli. J., 12: 503-510.

[18] Khattab A.A., M. I.M. Ibrahim, A. EL-Kady (2018). Ochratoxin A biosorption onto genetically improved of Lactobacillus delbrueckii mutants. International Food Res. J., 25: 515-522.

[19] Kolla J.P.N., M. Vijayalakshmi (2009). Chitinase production by Streptomyces sp. ANU 6277. Brazilian J. . Microbiol., 40: 725-733.

[20] Kotra S. R., V. Viharika, K.S. Reddy, P.V.D.S. Kumari, M. Lakshminadh., K.V. Rajesh, T.G. Sivasai, R.S. Lokesh (2013). Cost effective optimization of chitinase production using Streptomyces heteromorphus 4075: A progressive statistical approach. Pakhtunkhwa J. Life Sci., 1: 100-119.

[21] Kovalchuk I., O. Kovalchuk, B. Hohn (2000). Genome-wide variation of the somatic mutation frequency in transgenic plants. EMBO J., 19:4431-4438.

[22] Krieg David R. (1963). Ethyl methanesulfonate-induced reversion of bacteriophage T4rII mutants. Genet., 48:561.

[23] Kumar A. K. (2015). UV mutagenesis treatment for improved production of endoglucanase and $\beta$-glucosidase from newly isolated thermotolerant actinomycetes, Streptomyces griseoaurantiacus. Bioresour. Bioprocess., 22:1-10.

[24] Lim H., Y. Kim, S. Kim (1991). Pseudomonas stutzeri YPL-1 Genetic Transformation and Antifungal Mechanism against Fusarium solani, an Agent of Plant Root Rot. Appl. Environ. Microbiol., 57: 510-516.

[25] Lyutskanova D. G., M. M. Stoilova-Disheva, V. T. Peltekova (2005). Increase in tylosin production by a commercial strain of Streptomyces fradiae. Appl. Biochem. Microbiol., 41, 165-168.

[26] Mahadevan, B., D.L. Crawford (1997). Properties of the chitinase of the antifungal biocontrol agent Streptomyces lydicus WYEC108. Enzym. Microb. Tech., 20: 489-493.

[27] Makino, S.I., Y. Okada, T. Maruyama, S. Kaneko, C. Sasakawa, (1994). PCR-based random amplified polymorphic DNA fingerprinting of Yersinia pseudotuberculosis and its practical approach. J. Clin. Microbial. 32: 65-69.

[28] Mathivanan N., V. Kabilan, K. Murugesan (1998). Purification, characterization and anti-fungal activity from Fusarium chlamydosporum, a mycoparasite to groundnut rust, Puccinia arachidis. Can J Microbiol 44:646-651.

[29] Mendonsa E.S., P.H. Vartak, J.U. Rao, M.V. Deshpande (1996). An enzyme from Myrothecium verrucaria that degrades insect cuticle for biocontrol of Aedes aegypti mosquito. Biotechnol. Lett., 18:373-376. 
[30] Miyashita K., T. Fujii, Y. Sawada (1991). Molecular cloning and characterization of chitinase genes from Streptomyces lividans 66. J. Gen. Microbiol., 137: 2065-2072.

[31] Nagpure A., B. Choudhary, R.K. Gupta (2014). Chitinases: in agriculture and human healthcare. Critical Rev. Biotechnol., 34(3):215-232.

[32] Narasimhan A., S. Suresh, D. Bist, S. Shivakumar (2013). Enhancement of mycolytic activity of an antagonistic Bacillus subtilis through ethyl methane sulfonate (EMS) mutagenesis. Turk. J. Biol., 37: 323-328.

[33] Nawani N.N., B.P. Kapadnis (2005). Optimization of chitinase production using statistics based experimental designs. Process Biochem., 40: 651-660.

[34] Orunsi N.A., A.P.J. Trinci (1985). Growth of bacteria on chitin, fungal cell walls and fungal biomass, and the effect of extracellular enzymes produced by these cultures on the antifungal activity of amphotericin B. Microbiol 43:17-30.

[35] Qatan S.Y.A., A.A. Khatab (2019). Molecular Characterizaton of Streptomyces albogriseolus Excellent Mutants for Neomycin Producton, J. Pure Appl. Microbiol., 13: 1489-1498.

[36] Reynolds D.M. (1954). Exocellular chitinase from a Streptomyces sp. Microbiol., 11:150-159

[37] Robbins P.W., C. Albright, B. Benfield (1988). Cloning and expression of a Streptomyces plicatus chitinase (chitinase-63) in Escherichia coli. J. Biol. Chem., 263: 443-447.

[38] Saitou N., M. Nei (1987). The neighbor joining method: a new method for constructing phylogenetic trees. Mol. Biol. Evol. 4:406-425.

[39] Sambrook, J.; E.F. Fritsch and T. Maniatis (1989). Molecular Cloning; A Laboratory Manual, Second Edition Cold Spring Harbor.

[40] Subedi P., S. Simon, T. M. Rubin, P. Bharat, B. T. Kiran (2015). Sodium azide induced mutation of Actinomycetes II: Biochemical and Genetic Characterization. World J. Pharm. Sci., 3: 355-360.

[41] Subramaniam S., V. Ravi, G.K. Narayanan (2012). Studies on production of enzyme chitinase from Streptomyces sp. and its antifungal activity. J. Pharm. Res. 5(3):1409-1413.

[42] Sukalkar S.R., T.A. Kadam, H.J. Bhosale (2018). Optimization of chitinase production from Streptomyces macrosporeus M1. RJLBPCS, 4: 106-114.

[43] Taechowisan T., J.F. Peberdy, S. Lumyong (2003). Chitinase production by endophytic Streptomyces aureofaciens CMUAc130 and its antagonism against phytopathogenic fungi, Ann. Microbiol. 53: 447-461.

[44] Tarentino A.L., F. Maley (1974). Purification and properties of an endo-b-N-acetylglucosaminidase from Streptomyces griseus. J. Biol. Chem., 249: 811-817.

[45] Tsujibo, H., Y. Yoshida, K.Miyamoto, T. Hasegwa, Y. Inamori (1992). Purification and properties of two types of chitinases produced by an alkalophilic actinomycete. Biosci. . Biotechno. Biochem., 56: 1304-1305.

[46] Vetrivel K.S., K. Dharmalingam (2000). Isolation of a chitinase overproducing mutant of Streptomyces peucetius defective in daunorubicin biosynthesis. Can. J. Microbiol., 46: 956-960.

[47] Wang S., J. Hwang (2001). Microbial reclamation of shellfish wastes for the production of chitinases. Enzyme Microb Technol, 28: 376-82.

[48] Welsh, J., M. McClelland (1990). Fingerprinting genomes using PCR with arbitrary primers. Nucleic Acids Res., 18: 72137218.

[49] Yuli P.E., M.T. Suhartono, Y. Rukayadi, J.K. Hwang, Y.R. Pyun (2004). Characteristics of thermostable chitinase enzymes from the Indonesian Bacillus sp. 13.26. Enzyme Microb. Technol., 35:147-153. 